\title{
Role of International Assignment Exposure to Individual Development
}

Prof. Lubna Ambreen, Research Scholar, Bangalore University.

Asst. Professor, Al-Ameen Institute Of Management Studies, Bengaluru, M: 9742806085, email: lubnaambreen27@gmail.com.

\begin{abstract}
In the current globalized era international assignment is a part and parcel of every other organization dealing with international business. Talented workforce is the need of every organization and economies of world to meet the global criteria of excellence in foreign trade. International assignment to an expatriate is an experience of mixed bag. Where in the international assignment exposes the expatriate to a new culture, work environment and processes leading to enriching the individual experience contributing to overall development as an individual. The current paper focuses to analyze the contribution of international assignment exposure to the individual expatriate development in terms of skill, ability, and personality which otherwise might not be available with the domestic jobs holders and how this exposure reflects on expatriate behaviors which in turn would have an impact on employee performance individually and organizational effectiveness at large.
\end{abstract}

Key words: International Assignment, Expatriation, Expatriate Development, Individual development and International exposure.

\section{Introduction}

The international assignment exposure is a common scenario among the current working force, the various studies reveals that the international HR is in almost all the industrial sectors owing to FDI made in the countries across the globe from across the globe. Exchange of employees from one country to another is the essential characteristics of global HRM. The shift from one country to another exposes the employees for a foreign exposure where in the individuals get an opportunity to learn new work process, work culture, synergize ideas, coordinate and cooperate with individual of different stature, enhanced leadership skills, prepares the individuals to learn to face the contingencies, take up new and challenging job and get adjusted to an alien culture.In the current globalized era international assignment is a part and parcel of every other organization dealing with international business. And talented workforce is the need of every organization and economies of world to meet the global criteria of excellence in foreign trade. International assignment to an expatriate is an experience of mixed bag. Where in the international assignment exposes the expatriate leading to enriching the individual experience contributing to overall development as an individual.

The expansion of globalization has bearing on the internationalization of companies. There is a cumulative effect on foreign and Indian companies expanding their activities not only within the country but also on the international scale. This scenario has led to increase various new challenges in organization, including those allied to the international human resource management. Mounting activities outside the national borders challenges companies manage expatriation (assigning employees to work in a foreign subsidiary of a particular company for a specific period of time) and evaluate the process of expatriation. This process includes selecting the most proficient employees who have the necessary knowledge and, 
are open-minded and can act efficiently as well as adjust to a new environment quickly. After the completion of international tasks, the employees repatriate to their home country and continue their career in that same company or choose a different one according to the competencies and skills acquired during their international assignment. The Indian context as well shows that, as Indian companies are increasingly entering the international market, the executives and managers expatriates abroad is becoming more and more common. An increasing number of companies send their best employees to carry out various tasks in subsidiaries in foreign countries, as its working in an alien environment the foreign assignment is a learning experience. The current paper concentrates to analyze and understand the importance of foreign assignment exposure contributes to individual development of a repatriate as it's an opportunity for enhancing the knowledge and interpersonal skills along with gianing expertise in their respective field.

\section{Statement of problem}

As the global business is expanding significantly, the global activities of international human resource management is inseparable from the international assignments. As a result, an increasing amount of importance is attached to the outcome of assignment as the intention of a foreign assignment is not only filling in the position abroad but also to gain expertise from the foreign work process and environment. The employee on a foreign assignment is an expense to an organization as well to an individual who accepts the assignment in the foreign land, thereby if is significantly important to measure the outcome of an exercise which is different from the usual activity of a firm i.e., sending an employee to foreign country and taking an extra care of their whereabouts. The current study focuses to figure out the outcome of foreign assignment in terms of individual development of the repatriate post foreign assignment.

\section{Literature review}

For individual's career, work/life balance, development considerations, financial imperative and family motives are some of the factors expressively relate to the apparent career capital enlarged from assignments (Brewster, $C$ et al., 2008).One of most complex stages of the expatriation process is the adjustment of expatriates during the international assignment which has significant impact on the expectations or various failures and emergence of individual problems (Rocke, D. et al., 2015). The CEO international assignment experience is positively related to and is significantly moderated by the CEO's functional background. Specifically, CEOs with international assignment experience and an output functional background (e.g., marketing and sales) are positively associated with greater Corporate Social Performance (Dixon-Fowler, H. R. et al., 2009).Individuals who are high on extraversion improved their Cultural Quotient and behavioral Cultural Quotient more than did individuals who are low on extraversion. Similarly, individuals who are high on openness to experience improved their motivational Cultural Quotient more than did individuals who are low on openness to experience (Köksal, O. et al., 2014) mutual loyalty, mutual transaction, agent opportunism, and principal opportunism-and present a matrix of organizationindividual alignment to help predict varying degrees of success are the four basic configuration in expatriate assignment and in repatriation (Hall, D. T. et al., 2002).

\section{OBJECTIVES OF THE STUDY}

The primary objective of the study is to analyze the impact of international assignment exposure on individual development.

The sub-objectives are as follows:

1. To study the employee satisfaction post international assignment exposure.

2. To understand the level of employee selfevaluation. 


\section{SCOPE OF THE STUDY}

International assignment exposure is a common scenario in today's globalized world. Human Resource exposed to foreign assignments is found in all the industries. The study shall be conducted in the multinational enterprises in Bangalore.

- The study focuses on repatriates in Bangalore.

- It attempts to study the individual development post foreign assignment.

\section{RESEARCH DESIGN}

The research design adopted for the study is descriptive \& empirical in nature, leading to quantitative research.

\section{Methodology}

The study is carried out taking into consideration 20 repatriate form 5 MNCs in Bangalore city. The data for the study is collected from the aforesaid repatriates by exercising a structured questionnaire and the so collected data is analyzed by calculation mean and analyzed data is interpreted technically and suggested with suggestive measures.

- Survey Method: Mail survey method was adopted for collection of data.

- Sample Design: The industry considered for the collection of data for the study was IT sector in Bangalore.

- Sampling Technique: The sampling technique adopted for the study is snow ball sampling technique.

- Sample Unit: The sample unit of the study is the pool of repatriates from the Information Technology Sector.

- Sampling size: The sample size for the study is 20.

- Data Collection:

- Primary Data: The primary data for the study is collected through the structured questionnaire from the repatriates working in Information Technology sectors.
- Secondary Data: The secondary Data is collected from the national and international journals on Human Resource Management, International Human Resource Management and International Business. The articles from the various magazines like Human Capital, HBR, online magazines, books of national and international authors, thesis submitted to the different universities and web portals have been referred.

\section{Limitations of the Study}

- This study limits itself only to individual development achieved by the repatriates

- The data collected during the study both primary and secondary sources depend on the time factor and respondent's bias.

- During the conduct of the study natural biases are unavoidable.

- The study limits itself to Bangalore City.

\section{Findings}

The Indian repatriates as respondents in the study have been exposed to foreign assignment. Based on the objectives of the study the research is divided into factors leading to repatriates satisfaction and self-evaluation post foreign assignment exposure, the details of the findings are presented in the table below.

Table 1

Role of foreign assignment on self-development

\begin{tabular}{|l|l|l|l|}
\hline $\begin{array}{l}\text { SI. } \\
\text { NO }\end{array}$ & Particulars & Mean & $\begin{array}{l}\text { Total } \\
\text { Mean }\end{array}$ \\
\hline 1. & Repatriates Satisfaction & & \\
\hline & - I enjoyed foreign assignment & 4.5 & \\
& $\begin{array}{l}\text { I am pleased to express that I } \\
\text { had a foreign exposure }\end{array}$ & 4.5 & \\
& $\begin{array}{l}\text { I feel gratified with the } \\
\text { exposure I gathered during } \\
\text { foreign assignment }\end{array}$ & 4.4 & \\
& $\begin{array}{l}\text { I can see how I contribute to } \\
\text { the Company bottom line post } \\
\text { foreign assignment }\end{array}$ & 4.4 & \\
\hline
\end{tabular}




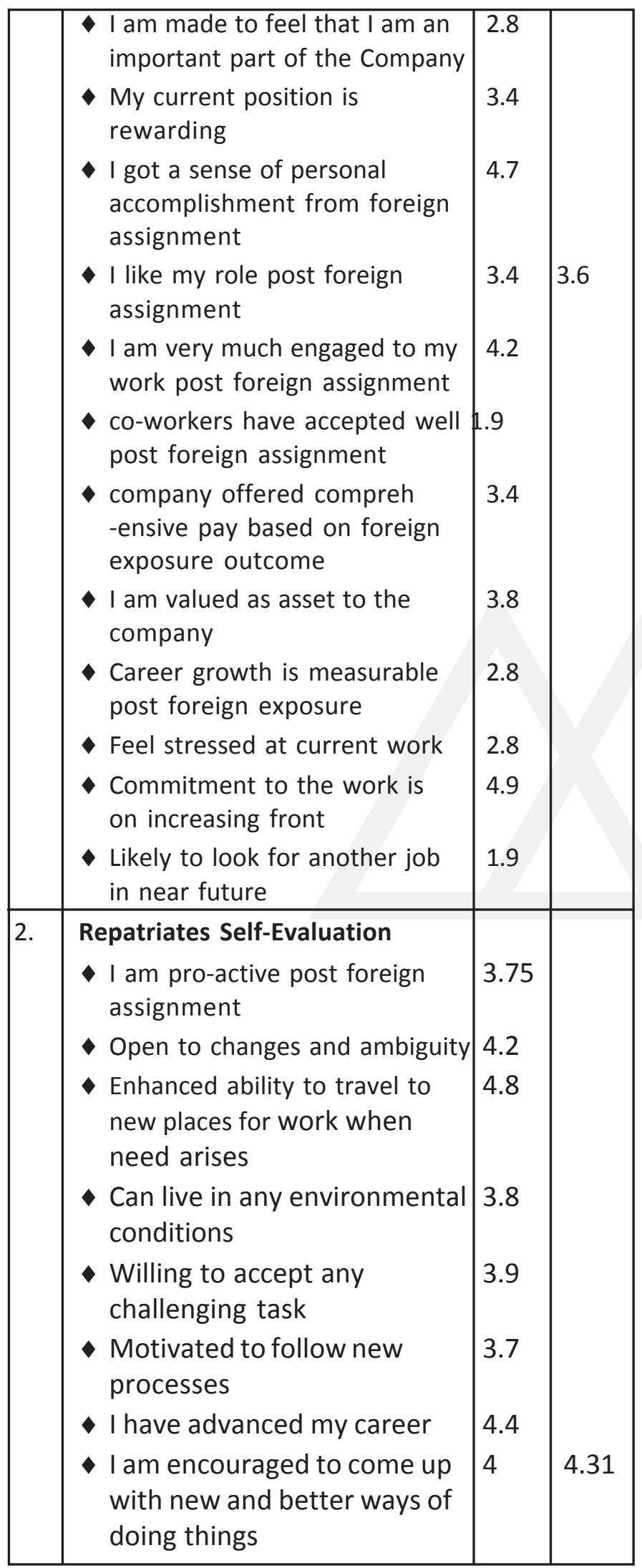

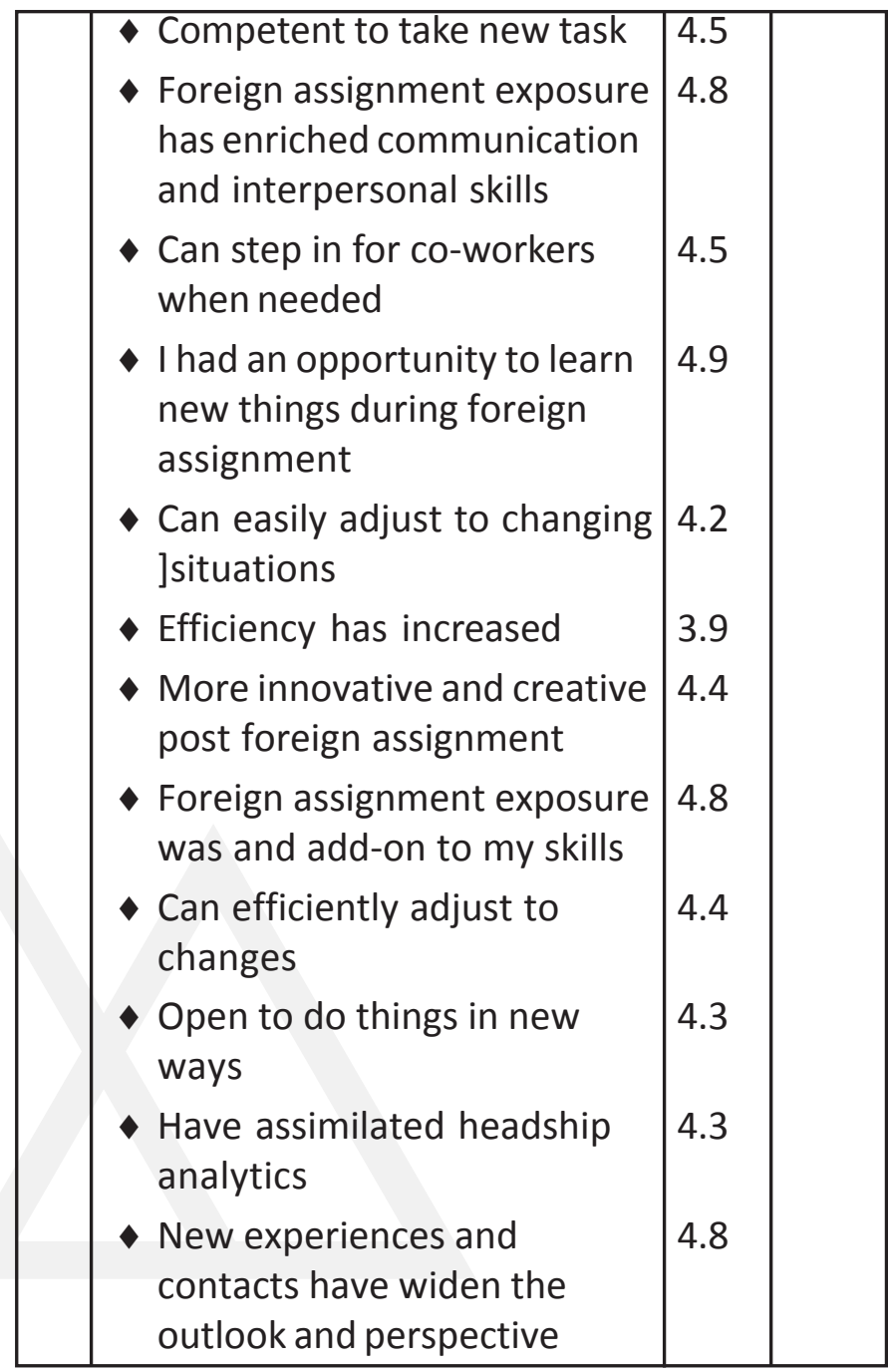

Source: created by the author on the basis of literature review

Note: All attributes were measured based on a 5point Likert scale.

The above Table showing the responses of respondents towards the attributes considered for variables: repatriates satisfaction and repatriates self-evaluation.

\section{Repatriate satisfaction}

The study reveals, respondents strongly agreed they enjoyed foreign assignment, they are pleased to express that they had a foreign exposure; they feel gratified with the exposure they gathered during foreign assignment they feel they contribute to the Company bottom line post foreign assignment, they 
sensed personal accomplishment from foreign assignment, they liked their role post foreign assignment and very much engaged to work post foreign assignment and their Commitment to the work is on increasing front. Most of the respondents agree thier current position is rewarding,company offers comprehensive pay based on foreign exposure outcome and valued as asset to the company. Whereas respondents are neutral about they are made feel important part of the company, neutral in their response towards growth is measurable post foreign exposure and Feel stressed at current work.But most of the respondents disagree that thier co-workers have accepted well post foreign assignment. Respondents are not likely to look for another job in near future.

Whereas the total mean of repatriation reveals satisfactions reveals that most of the respondents agree they are satisfied post international assignment exposure.

\section{Repatriate self-evaluation}

Most of the respondents strongly agree that they are Open to changes and ambiguity, Enhanced ability to travel to new places for work when need arises, they have advanced their career prospect, they are encouraged to come up with new and better ways of doing things, Competent to take new task, foreign assignment exposure has enriched communication and interpersonal skills, can step in for co-workers when needed, had an opportunity to learn new things during foreign assignment, can easily adjust to changing situations, More innovative and creative post foreign assignment, foreign assignment exposure was and add-on to their skills, Can efficiently adjust to changes, open to do things in new ways, have assimilated headship analytics, New experiences and contacts have widen the outlook and perspective.

Most respondent's agree they are pro-active post foreign assignment, can live in any environmental conditions, willing to accept any challenging task, Motivated to follow new processes, Efficiency has increased.
The survey with respects to repatriate self-evaluation results, all the respondents are on agreeing side and no response towards neutral or disagreeing side. Thereby we can conclude that all the respondents are self-developed to evaluate themselves well.

Whereas the total mean of repatriation selfevaluation reveals that most of the respondents strongly agree they have self-developed post international assignment exposure.

\section{Conclusion}

The current study focused on individual development gained via foreign assignments in foreign country. The paper has exposed most of their respondents agree that they are satisfied post assignment and strongly agreed that there stay in the foreign land was fruitful and helped them to develop individually for better performance in their career. Further the research has discovered that their co-workers have not accepted them on return from the foreign assignment. The assignment has given them the confidence to start any new process as well take up their colleagues work when required, adaptable to change and can survive in any environment. These are the characteristics of a developed individual and hereby it can be concluded that international assignment exposure leads to contributes to repatriate satisfaction and development as an individual.

\section{Scope for further research}

Possible research can be conducted to understand influential factors contributingfor individual development during the foreign assignment.

\section{References}

1) Dickmann, M., Doherty, N., Mills, T., \& Brewster, C. (2008). Why do they go? Individual and corporate perspectives on the factors influencing the decision to accept an international assignment. The International Journal of Human Resource Management,, 19(4), 731-751.

2) Sarkiunaite, I., Rocke, D. (2015), "The Expatriate Experience: the Factors of International 
Assignment Success", Transformations in Business \& Economics, Vol. 14, No 1 (34), pp.2047.

3) Slater, D. J., \& Dixon-Fowler, H. R. (2009). CEO international assignment experience and corporate social performance. Journal of business ethics, 89(3), 473-489.

4) ?ahin, F., Gurbuz, S., \& Köksal, O. (2014). Cultural intelligence (CQ) in action: The effects of personality and international assignment on the development of CQ. International Journal of Intercultural Relations, 39, 152-163.

5) Yan, A., Zhu, G., \& Hall, D. T. (2002). International assignments for career building: A model of agency relationships and psychological contracts. Academy of Management Review, 27(3), 373-391.

6) Lovvorn, A. S., \& Chen, J. S. (2011). Developing a global mindset: The relationship between an international assignment and cultural intelligence. International Journal of Business and Social Science, 2(9).

7) Lupo, P. J., Symanski, E., Chan, W., Mitchell, L. E., Waller, D. K., Canfield, M. A., \& Langlois, P. H. (2010). Differences in exposure assignment between conception and delivery: the impact of maternal mobility. Paediatric and perinatal epidemiology, 24(2), 200-208.
8) Takeuchi, R., Tesluk, P. E., Yun, S., \& Lepak, D. P. (2005). An integrative view of international experience. Academy of Management Journal, 48(1), 85-100.

9) Peter j.dowling, denice e.welch, "international human resource management: managing people in a multinational context", fourth edition 2004, thomson learning, pg. 5.

10) Jesse e. Olsen and luis I. Martins, "the effects of expatriate demographic characteristics on adjustment: a social identity approach", human resource management, march-april 2009, vol. 48, no. 2, pp. 311- 328 (C) 2009 wiley periodicals, inc. Published online in wiley interscience (www.interscience.wiley.com). Doi: 10.1002/ hrm.20281

11) Gunter k. Stalh, edwin I. Miller, rosalie I. Tung (2001), "toward the boundryless carreer: a closer look at the expatriate career concept and perceived implications of international assignments", printed at insead, fontainebleau, france

12) Andersson, et al "effective repatriation" - a case study of volvo construction equipment in eskilstuna, jönköping 2006-10-15 